\title{
LA PROSA AUTOBIOGRÁFICA DE BLAS DE OTERO, HISTORIA (CASI) DE MI VIDA (1969): LA CONSTRUCCIÓN DE LA SUBJETIVIDAD
}

Lucía Montejo Gurruchaga

UNED

lmontejo@flog.uned.es

\section{RESUMEN}

La Obra Completa (1935-1977) de Blas de Otero, publicada en enero de 2013, reúne los doce libros del poeta: ocho publicados en vida del autor, los poemas de la obra póstuma Hojas de Madrid con La galerna, a los que se añaden ahora los inéditos Poesía e Historia, Nuevas historias fingidas y verdaderas y la autobiografía Historia (casi) de mi vida, un pequeño libro en prosa, una autobiografía atípica escrita en 1969. El rico material de su escritura autobiográfica está integrado por un selectivo corpus de reflexiones expresadas con una sucinta economía narrativa. Presenta en su discurso autobiográfico una visión fragmentada de su existencia. Registra y calla en la misma medida, tanto en lo que respecta a su vida privada como a la pública.

Palabras Clave: Blas de Otero. Siglo XX. Autobiografía.

\section{AbStRact}

Blas de Otero's (1935-1977) Obra Completa [Complete works] published in January 2013 gathered his twelve books — eight of them were published during his lifetime, the poems from Hojas de Madrid con La galerna [Madrid's leaves with The gale] were posthumously edited, and the unpublished Poesía e Historia [Poetry and History], Nuevas historias fingidas y verdaderas [New false and true stories] and the prose small 
atypical autobiography Historia (casi) de mi vida [Story (almost) of my life] written in 1969 are now added. His rich autobiographical writing consists of a selective corpus of reflections expressed with a concise narrative economy. He presents a fragmented view of his existence as he records and elides to the same extent, both regarding his private and public life.

Keywords: Blas de Otero. $20^{\text {th }}$ Century. Autobiography.

La Obra Completa (1935-1977) de Blas de Otero publicada por Galaxia Gutenberg/ Círculo de Lectores en enero de 2013, edición de Sabina de la Cruz y Mario Hernández, reúne los doce libros del poeta: ocho publicados en vida del autor -Cántico Espiritual, Ángel fieramente humano, Redoble de conciencia, Pido la paz y la palabra, Ancia, En castellano, Que trata de España, Historias fingidas y verdaderas-, los poemas de la obra póstuma Hojas de Madrid con La galerna, compuesta por 306 poemas escritos en Madrid entre 1968 y 1977 y que fueron publicados por la misma editorial en $2010^{1}$, a los que se añaden ahora tres volúmenes inéditos, Poesía e Historia, que incluye más de ochenta poemas escritos entre 1960-1968, Nuevas historias fingidas y verdaderas, compuesto por 28 prosas escritas entre 1971y 1972, y la autobiografía velada Historia (casi) de mi vida, un pequeño libro en prosa, escrito en 1969, poco después de regresar de $\mathrm{Cuba}^{2}$. A estos inéditos hay que añadir el anexo titulado «Complemento», un conjunto de más de cien poemas inéditos y dispersos escritos entre 1935 y $1963^{3}$. Los editores han respetado el nivel de exigencia que el poeta defendió siempre y por un criterio de rigurosa selección han dejado fuera composiciones que el autor hubiera considerado textos inacabados, borradores o composiciones escritas en circunstancias históricas de urgencia y que nunca llegaron a formar parte de sus libros o de sus antologías. Aunque se trata de un cierre excepcional para este volumen ejemplar y muy

${ }^{1}$ Blas de Otero, Hojas de Madrid con La galerna. Edición de Sabina de la Cruz, prólogo de Mario Hernández, Barcelona: Galaxia Gutenberg / Círculo de Lectores, 2010. Una parte de los poemas que lo componen se habían ido publicando en antologías y en publicaciones periódicas, pero más de la mitad permanecían inéditos.

${ }^{2}$ Las primeras secuencias de Historia las pudimos leer en Ancia. Revista de la Fundación Blas de Otero, II, 3 (2004), pp. 73-75.

3 Sabina de la Cruz detalla en el apartado «Sobre esta edición» de la Obra Completa (1935-1977) de Blas de Otero, los criterios que ella y Mario Hernández han seguido para abordar la edición de la obra completa no perdiendo de vista el principal: «la búsqueda de las señales de la voluntad del poeta de acuerdo con los métodos de la crítica textual». Se detienen con especial cautela en la sección que denominan «Complemento», en la estela de Juan Ramón Jiménez, en la que han abordado «una de las tareas más comprometidas: la búsqueda, recopilación y selección de textos inéditos y dispersos, y la ubicación y ordenación de los publicados y dispersos en revistas o en antologías propias o colectivas», compuestos entre 1935-1963, y que han ordenado en cinco ciclos; los tres primeros, entre 1935-1952, reúnen más de ochenta, y el número baja sensiblemente en los dos últimos, que reúnen veintiuno. Sorprende que no hayan encontrado ni inéditos ni dispersos desde 1963 hasta la muerte del poeta en 1979. El lector interesado encontrará algunos poemas que cumplen estos criterios y no han sido incluidos en la Obra Completa en mis artículos: «Blas de Otero y la censura española desde 1949 hasta la transición política. Primera parte: de Ángel fieramente humano a En castellano». Revista de Literatura, LX, 120 (1998), pp. 491-516; «Blas de Otero y la censura española desde 1949 hasta la transición política: Segunda parte: de Que trata de España (1964) a Todos mis sonetos (1977). Revista de Literatura, LXII, 123 (2000), pp. 155-175. «Blas de Otero en las revistas literarias de los años cincuenta». Boletín de la Fundación Federico García Lorca, 35-36 (2005), pp. 231-250 y «Algunos poemas inéditos de Blas de Otero correspondientes a la primera etapa de su creación». Epos, XXIV (2008), pp. 105-115. 
próximo a las intenciones del autor, coincido con Juan José Lanz en que hay algunas ausencias poco justificadas ${ }^{4}$.

Otero no es un poeta de dilatada producción. Ha ido moldeando sus libros de un modo sostenido, selectivo a través del tiempo, ajeno a urgencias, conjugando una intensidad existencial y una sosegada meditación, y haciendo crecer una trayectoria de forma natural, ajustada a sus necesidades expresivas, en constante indagación de los principios estéticos que iban rigiendo su creación, y en profunda fidelidad, coherencia y unidad interna. Por este motivo sorprende hallar tanta obra inédita y más aún que no haya visto la luz hasta pasados más de treinta y cinco años desde su muerte.

Voy a centrar mi análisis en uno de los tres libros inéditos, la autobiografía Historia (casi) de mi vida, que consciente y premeditadamente está lejos de ser una ceñida fuente documental.

Son escasos los estudios que se han dedicado a la prosa oteriana aunque las primeras composiciones en prosa son tempranas en su creación, las encontramos ya en Ancia e irá deslizando algunas otras en sus libros posteriores ${ }^{5}$. Aunque en los primeras obras la presencia de la prosa es intermitente y escasa, su uso será sostenido y fértil tras la publicación de Historias fingidas y verdaderas. Este primer libro en prosa, editado a finales de 1970, innovador, radical y complejo, ha generado algunos estudios de interés ${ }^{6}$.

En la Obra Completa el lector descubre que Historias fingidas y verdaderas no es el único libro en prosa del poeta, sino que, en los últimos años ha ido simultaneando verso y prosa. En esta etapa de culminación creadora ha escrito las prosas de Historias fingidas y verdaderas (1966-1968), los poemas de Hojas de Madrid con La galerna (1968-1977), la prosa autobiográfica Historia (casi) de mi vida (1969) ${ }^{7}$, sucinta obra en la línea de la escritura autobiográfica, y Nuevas historias fingidas y verdaderas (1971-1972), en la estela de las primeras. Todas sus prosas surgen de forma paralela y simultanea a su verso; de una estética y una poética comunes brotan dos representaciones formales. «La prosa es una fuente que mana pan, así como la poesía es un pan del que fluye una fuente», sostiene el poeta en «Para toda una vida» de Hojas de Madrid con La galerna, con lo que parece querer decirnos que baraja los mismos principios aunque en orden distinto; en su prosa ensambla y entreteje los recursos de escritura

\footnotetext{
4 Juan José Lanz, «Mapa total de Blas de Otero», El País, Madrid, 22 de mayo de 2013, pp. 1-4.

5 Son las tituladas «Otra historia de niños para hombres» y «La Monse», en Ancia; «Papeles inéditos» y «Últimas noticias» en En castellano; «Colliure 1959» en Que trata de España; «El espectro de Neruda», «Redención del viento» en Poesía e Historia.

${ }^{6}$ Geoffrey Ridle Barrow, «Una velada paradoja: Historias fingidas y verdaderas». Papeles de Son Armadans, Palma de Mallorca, CCLIV-CCLV, (mayo-junio, 1977), pp. 253-271; Sabina de la Cruz, «Introducción» a Historias fingidas y verdaderas. Madrid: Alianza, 1980, pp. 7-23; Marta Ferrari, «El juego más peligroso: Historias fingidas y verdaderas, de Blas de Otero». Ínsula [monográfico dedicado a Blas de Otero], 676-677 (2003), pp. 47-48; Gonzalo Sobejano, «Blas de Otero y el poema en prosa «Las nubes», «Vivir para ver». Ínsula, [monográfico dedicado a Blas de Otero], 676-677 (2003), pp. 49-51; Lucía Montejo Gurruchaga, «La última etapa de la creación de Blas de Otero: Historias fingidas y verdaderas y los poemas de Hojas de Madrid con la galerna», Unamuno, Otero, Aresti, eds. Jon Kortazar y Juan José Lanz. Bilbao, Ayuntamiento de Bilbao, 2003, pp. 91-105; Fernando Valls, «De vez en cuando, un elefante blanco... Para leer las Historias fingidas y verdaderas». Compromisos y palabras bajo el franquismo. Recordando a Blas de Otero (1979-2009), eds. Araceli Iravedra y Leopoldo Sánchez Torre. Sevilla, Renacimiento, 2010, pp. 135-164.

7 Sabina de la Cruz, en las «Notas» de la Obra Completa, op. cit, p. 1174, fija la fecha de composición entre febrero y octubre de 1969.
} 
que ha explorado en cada uno de sus libros. Enriquece su prosa con los hallazgos de su verso, aprovecha elementos constitutivos temáticos y formales de los poemarios para recrearlos en su creación en prosa. En Historia (casi) de mi vida se va a mostrar como un autobiógrafo atípico.

Durante las últimas décadas, la bibliografía crítica sobre los discursos autobiográficos ha experimentado un crecimiento más que sensible. La diversidad de perspectivas críticas ha producido un amplio abanico de conclusiones que ha supuesto un desplazamiento de la concepción del hecho autobiográfico desde una inicial fidelidad absoluta a la referencialidad hasta la asunción de esta escritura como una ficción más ${ }^{8}$. Eakin cree que el texto no refleja a ningún autor, sino que todo autor se crea a sí mismo en un yo que no podría existir de otro modo: «toda mímesis es necesariamente producto de la ficción» ${ }^{9}$. Estudios recientes identifican tres grandes etapas en la teoría autobiográfica. En la primera, «la crítica se centró en el bios, bajo una pretensión (...) de todo escrito autobiográfico de reproducir lo más fehacientemente y con el máximo de fidelidad una vida. La segunda fue el autos y, por tanto, el centro de referencia estará en la relación del texto con el sujeto creador. El tercero pone el punto de mira en el graphé acentuando el alejamiento de las nociones de referencialidad al considerar que el fundamento de la autobiografía era que en ella el autor no se interpreta ni se reconstruye, sino que se crea a sí mismo ${ }^{10} \gg$. Paul De Man ha defendido esta idea con vehemencia argumentando que no existen diferencias entre los textos ficcionales y los autobiográficos ${ }^{11}$. Lejeune definió la autobiografía en 1975 como «relato retrospectivo en prosa que una persona real hace de su propia existencia, poniendo énfasis en su vida individual y, en particular, en la historia de su personalidad», que contiene, de manera unitaria y lineal, circunstancias y vivencias acaecidas a un individuo a lo largo de su existencia siguiendo el orden cronológico en el que se fueron sucediendo y en ella entran en juego, por tanto, elementos diferentes tales como el tema tratado - historia de una vida-, la situación del autor — su identidad, que se corresponde con una persona real, y del narrador-, la posición del narrador —identidad del narrador y del personaje principal— y la forma del lenguaje — relato en prosa- La correspondencia entre los tres elementos queda asegurada a través del «pacto de lectura autobiográfico» que se establece desde el momento en que el autor confirma a los lectores que la vida que va a contarles es la suya ${ }^{12}$. Desde el momento que el lector acepta el pacto de lectura, es evidente que, desde el punto de vista formal, no hay rasgos que permitan diferenciar la ficción de la autobiografía. El punto de partida del sujeto a la hora de organizar la autobiografía es la dicotomía verdad / mentira. Declara que no hará una manipulación interesada de los hechos aunque esos hechos puedan sufrir cambios por la incorporación de elementos que nutren la escritura evocadora:

${ }^{8}$ Eakin, Paul John, En contacto con el mundo. Autobiografía y realidad. Madrid, Megaluz - Endymion, 1994, pp.40-42.

9 Eakin, Paul John, «Autoinvención en la autobiografía: el momento del lenguaje». Anthropos Suplemento, 29 (1991), pp. 73-91.

${ }^{10}$ Tortosa, Virgilio: Escrituras ensimismadas. La autobiografía literaria en la democracia española. Alicante, Universidad de Alicante, 2001, p. 41.

11 Paul De Man: La resistencia a la teoría. Madrid, Visor, 1990.

12 Philippe Lejeune, Le pacte autobiographique. Paris, Seuil / Poétique, 1975, p. 14. 
[...] Escribir la historia de mi vida podría resultar escandaloso para los demás, que no aman la terrible sinceridad, mas no para mí, que toda mi vida me hundí hasta tocar el fondo, con un lema único: Prefiero una verdad desagradable a una mentira agradable.

Yo diré siempre la verdad, no sé si toda, y sin ofender a ningún hombre o mujer que se hayan cruzado o convivido conmigo. La verdad que no pretendo objetiva, pues esto ¿quién lo sabe? Seguramente no lo sabe ni dios (p. 955).

El poeta, que pronto se propuso representar la realidad, compartir la ardua lucha del hombre, se impuso entonces una regla de vida-obra, la exigencia y el compromiso de identidad del yo como fundamento de verdad. Ese principio lo formuló en el poema «Prefacio» de Ancia: «Escribo con el cuello llameante / y cuelgo de los labios las parábolas / para que vean que me explico en sangre / y silabeo de verdad, en plata [..]», lo reiteró en Pido la paz y la palabra: «Ni una palabra / brotará de mis labios / que no sea / verdad. / Ni una sílaba / que no sea / necesaria. [...]», en «Libertad supone o significa» y, poco después, en En castellano: «Siempre os he dicho / verdad. Cuerpo / presente en todo lo que toco.»

En Historia (casi) de mi vida la voz narrativa transita con entera libertad por el sistema de géneros configurados como compartimentos estancos y frente al orden cronológico del relato autobiográfico impone el discurrir libre y caprichoso de la memoria, frente a la rememoración completa de una vida, presenta una visión fragmentada de su existencia, sin series cronológicas fiables. Afronta la práctica del género autobiográfico desde su condición de poeta e imprime en el discurso narrativo su aliento poético; no considera el género autobiográfico como género cerrado y excluyente, sino abierto e integrador de otros géneros. Contagia la prosa de tensión poética porque el aprendizaje lírico que ha atesorado en su verso revierte en beneficio de su creación en prosa, y ensaya novedades formales, como colocar al frente del libro una sentencia, dar cabida al verso en un texto en prosa intercalando dos sonetos, o cerrar la autobiografía con un «Epílogo» inconcluso ${ }^{13}$.

${ }^{13}$ La sentencia — «... con todos mis errores acerté el camino»— procede de la prosa «Seguir siguiendo» de Historias fingidas y verdaderas. El primer soneto, «Historia de mi vida», obedece a su deseo de condensar en catorce versos su experiencia vital presente. Pertenece a Hojas de Madrid con La galerna. El segundo soneto, que integra en el discurso sin apuntar el nombre de su autor ni aportar otros indicios para que el lector lo pueda reconocer, titulado «A la muerte de Torrijos y sus compañeros», lo compuso Espronceda poco después del fusilamiento de Torrijos, circunstancia que Otero rememoró en el poema «Españahogándose» de Que trata de España. Estamos ante una de las técnicas que caracterizan su poesía, la inserción en sus textos de palabras procedentes de otros textos, la sinfonía de voces ajenas que se mezclan y disuelven en su propia voz. Los distintos procedimientos de intertextualidad que en su obra se hacen patentes, las distintas formas en que suelen presentarse y los valores que adquieren han sido atendidas y esclarecidas por la crítica. Citaré solo algunos de los estudios que considero fundamentales: Evelyne Martín Hernández, «Un cas de «transfusión» poétique: César Vallejo - Blas de Otero». Iris, Montpellier, 1 (1981), pp. 7-34. Sabina de la Cruz, Blas de Otero: contribución crítica a una edición de su obra. Madrid, Universidad Complutense, 1983, 2 vols. (tesis doctoral inédita). Ángel González, «La intertextualidad en la obra de Blas de Otero», en José Ángel Ascunce Arrieta (coord.), Al amor de Blas de Otero. Actas de las II Jornadas Internacionales de Literatura: Blas de Otero. San Sebastián, Mundaiz, 1986, pp. 63-75. Lucía Montejo Gurruchaga, cap. 3. «Presencias intertextuales». Teoría poética a través de la obra de Blas de Otero. Madrid, Universidad Complutense, 1988, pp. 316-644 y «La huella de Juan Ramón Jiménez en la obra de Blas de Otero». Anuario de Letras, México, vol. XXVIII (1990), pp. 307-325. Juan José Lanz, «Bajo el signo de Collioure: los poetas sociales ante Antonio Machado: de Gabriel Celaya a Blas de Otero». Bulletin Hispanique, vol. 114, 2 (2012), pp. 703-748. Fernando Valls, De vez en cuando, un elefante blanco... Para leer las Historias fingidas y verdaderas. Compromisos y palabras bajo el franquismo. Op, cit, 2010,135-164. 
$\mathrm{El}$ «yo», en tanto sujeto del discurso representado, va pulsando su eco en ese «tu» o «Vosotros», tantas veces buscado por la escritura oteriana. Se apela al otro para presentarle la verdad de lo que uno es, para justificarse ante los demás. Podría haberse ocultado tras una máscara, tras un «alter ego» que le suplantase, pero desecha este recurso y prefiere mostrar su identidad, con lo que subraya la actitud decididamente autobiográfica con que acomete estas prosas que obedecen al deseo de condensar en ellas —en sentido introspectivo y libre- (casi) toda la experiencia vital, con ese título elegido, como siempre hiciera, de forma consciente y meditada y que consideramos, en este caso, justifica y legitima el texto dentro del grupo genérico al que pertenece. Involucra al lector — como ya había hecho en el verso- - y le hace partícipe de sus vivencias; unas veces le asigna la función de confidente, otras busca en él la compañía de un viejo amigo que mitigue su soledad, le incorpora al hilo de sus cavilaciones; subyace, en muchas ocasiones, la necesidad de sentirse comprendido. Se dirige a él con frases como las siguientes: «Me voy a París, te digo que me voy a París (p. P. 954)», o «Pasemos el Sena arrebujados en la niebla (p. 957)»o «Ya sabéis que el valle de Orozco...(p. 960)» o «Volvamos a los versos (p. 961)».

El rico material de su escritura autobiográfica tiene un selectivo corpus de reflexiones, una suma de experiencias. El lector que conoce su obra lírica, le será difícil encontrar en su autobiografía hechos o circunstancias que no hayan sido objeto de su poesía aunque fluyan en dos estratos diferentes. El narrador acumula sensaciones, evoca y describe espacios de libertad que vertebran sensaciones y recuerdos del desarrollo vital de la infancia y la juventud. Otero, siempre parco en confidencias y poco proclive al desahogo íntimo, pone en marcha el mecanismo de su memoria y, como en un continuum temporal, evoca recuerdos y circunstancias del pasado remoto de su primera infancia, algunos gozosos, otros tristes episodios de huella perenne que acuden, como en conjunto selecto de detonaciones perturbadoras, que no dependen de su voluntad; recuerdos imborrables que fluyen con perfiles bien definidos: el primer hogar, «aquella casa con terraza y pérgola que construyó mi padre en los años de la primera guerra, que tan provechosa resultó para los industriales y almacenistas bilbaínos» (p. 953), «el gran Rolls-Royce que tenía mi padre a cuenta de la guerra europea, y me regaló una Pathé-Baby en la que vi las primeras películas de Charlot, y luego vino mademoiselle Isabel del Sur de Francia» (p. 957), las primeras letras de Preparatorio e Ingreso de Bachillerato con los jesuitas, que «me inculcaron una piedad sentimentaloide y terrorífica» (p. 960), el traslado a Madrid con su familia en 1927 en un intento de recuperar la fortuna perdida, el primer amor, jarroncito de porcelana, que el poeta rememora de forma precisa, minuciosa. La infancia se percibe como pasado mítico, como tiempo detenido, concluso, reconstruida con perfiles nítidos, y la nostalgia es la idea motriz del mundo infantil visto por el sujeto adulto ${ }^{14}$.

${ }^{14}$ Hay algunas biografías a las que remito al lector interesado. La más completa la encontrará en «La vida de un poeta», que forma parte de la «Introducción» a Blas de Otero, Poesía escogida. Edición de Sabina de la Cruz y Lucía Montejo Gurruchaga. Barcelona, Vicens Vives, 1995 (2 $2^{a}$ ed. corregida, 2000), pp. IX-XIX. Aportan asimismo datos de interés los estudios siguientes: Sabina de la Cruz, «Notas biográficas. Tabla cronológica de la vida y obra de Blas de Otero (1916-1979)», Ancia, II, 4 (2004), pp. 6-73; Sabina de la Cruz, «II. La vida de un poeta», en Blas de Otero, Obra Completa (1935-1977), op. cit, pp. 57-77. Lucía Montejo Gurruchaga, Cap. 1: «Paralelismo vida-obra» en Teoría poética a través de la obra de Blas de Otero. Op. cit., pp. 1-122. Elena Perulero, «Porvenir y Brisa»: Sabina de la Cruz con Blas de Otero». Entrevista recogida en el Homenaje a Blas de Otero. Boletín de la Fundación Federico García Lorca, 43 (2008), pp. 191-214. 
[...] Ahora estoy en Madrid, en el colegio de la calle de Atocha, donde conocí a María del Carmen, jarroncito de porcelana, que tanto iba a suponer en toda mi vida sentimental y hasta poética. Era una chiquilla encantadora, con un trajecito verde con cuello de puntilla blanca, cutis de sèvres y pechitos apenas insinuados. Era la imagen de la santísima virgen y del niño Jesús al mismo tiempo, pero nosotros nos íbamos al Retiro a retozar en los verdes bancos o entre los troncos; todas las noches, a la salida de la clase, la acompañaba hasta su portal en Espoz y Mina (p. 953).

Pasa, como de puntillas, por algunas de las circunstancias más dolorosas de este pasado remoto: la muerte del hermano mayor «en plena adolescencia, alevoso crimen no sé de quién», la muerte del padre dos años después «fuera de casa», la vuelta a Bilbao con su madre y sus hermanas cuando el poeta tiene quince años: «estamos vendiendo hasta la última silla en el piso de la calle Leganitos»(p. 962), confiesa al lector. Un fenómeno constante de su carácter reflexivo, que desarrolla en toda su trayectoria poética, son los estados anímicos que suscitan los lugares. La reflexión sobre el espacio evocador de su recuerdo es recurrente. Se demora en los vivos sentimientos que le despierta la evocación de Orozco, el pueblo vasco motivo de varias secuencias, y de distintas composiciones de su obra lírica, cuna de sus antepasados por rama materna, lugar de vacaciones estivales al amparo de la casa de la abuela. Es el rincón propicio donde absorber el latido cotidiano, donde desarrolla facultades sensoriales, donde se deja envolver por la alegría, por el silencio y el apartamiento, hasta convertir su paisaje en un «estado de alma». Como desterrado, como vagamundo durante tantos años, el sujeto narrativo añora la tierra que ha dejado atrás, la tierra donde ha construido su identidad y resignadamente sueña que allí aguarda la muerte inexorable ${ }^{15}$ :

[...] Mi madre nació en Orozco (Vizcaya), mi abuela doña Pepita había casado con José Ramón Muñoz, del Duranguesado, un médico célebre en el Bilbao de fines y principios del siglo. Ya sabéis que el valle de Orozco es uno de los lugares más suaves de mi memoria [...]. Jugué mucho al frontón en Orozco, anduve mucho entre helechos, árgomas, zarzamoras, bajo los castaños, robles, entre los frutales del huerto de la abuela [...] (961).

[...] Estoy sentado a la puerta del palacio de Orozco, viendo pasar mi entierro. Lo estoy mirando pasar con toda serenidad, algún día tenía que ser, así, sin chanfainas de ningún tipo, arropándome la tierra madre, la tierra que brotará hierba y sobre la que descenderá la lluvia desmenuzada, como yo, de mi pequeña patria (p. 967).

La Guerra Civil es otro episodio fundamental en esta autobiografía pues de las dieciséis secuencias que la componen, en cuatro aparece como motivo. La guerra sorprende al poeta con la carrera de Derecho recién terminada. Se incorpora como sanitario a las batallones vascos y cuando las tropas del general Franco entran en Bilbao, es enviado al frente de Levante. De forma fluida, segura, sin titubeos, la voz narrativa registra nombres, lugares, datos, testimonios, anécdotas, detalles que aportan una dimensión pragmática fundamental, y descubren al lector un narrador fiable, que da testimonio de unos hechos. Evoca esos duros tiempos desde el presente, introduce reflexiones actuales (en el tiempo

15 Sobre la importancia de esta localidad en la obra oteriana vid., Juan José Lanz, «La ciudad de memoria: imaginario urbano y lucha de clases en la obra de Blas de Otero». Blas de Otero: nuevas lecturas críticas. Ínsula, 676-677 (abril-mayo 2003), pp. 23-24. 
de la escritura) sobre las terribles consecuencias históricas de la obstinación política y religiosa, juicios severos de tremenda contundencia de quien luchó para realizarse en el contexto adverso de la España de Franco.

Tiempo terrible de la guerra. Te recuerdo en Alcañiz, montados en los horribles camiones que nos llevaron hasta Vinaroz, bajando junto a Morella y las hoscas hondonadas de piedra, espino y hierbajos, bajo un cielo duramente azul. ¿Voy a hablar de la guerra, de esa gran cabronada que nos armaron cuatro militares, ocho terratenientes y cinco curas, con el respaldo del hijo de puta de Hitler? No, no voy sino a recordar Bilbao asediado por los requetés, yo en mi batallón vasco, acaso solo por la fina y triste lluvia que tanto amé siempre (p. 954). [...] Pero no quiero hablar de nuestra guerra, ni de lo que siguió, que casi fue peor. [...] Al sur de Castellón de la Plana, $4^{\text {a }}$ batería de obuses 149/12, del 12 Regimiento de Artillería Ligera, de Logroño (qué complicado es esto). Algarrobos, cielo azul. Nules. Al otro lado del cerro, Sagunto. Chupinazos a todo pasto. Nos refugiamos en las trincheras, la metralla vuela por todos lados. Una explosión a la entrada de la chabola de los telefonistas. No puedo contenerme y corro hacia allá, pues imagino haya heridos. Los encuentro contando chistes verdes. En mayo nos trasladan al frente de Guadalajara, sembrado de baterías. Se prepara el último golpe contra Madrid. Un mediodía, estando tomando el rancho, vemos aparecer telas blancas en las lomas. La guerra, al carajo, ha terminado. Estamos perdidos lo menos para treinta años (p. 964).

El año 1952 es crucial para la vida y la obra del poeta bilbaíno. Por primera vez sale de España con destino a París, donde entrará en contacto con los exiliados comunista españoles y residirá algo más de un año, momentos mucho más desdibujados que los de la infancia y la adolescencia ${ }^{16}$. «Me voy a París aunque tenga que vender mi biblioteca. Y la vendí», confiesa al lector, y añade con humor: «lástima de franceses, que lo único que saben hacer mejor que yo es pronunciar el francés. Mis ruadas interminables por el Luxemburgo, los bulevares, el Sena, las grises callejuelas de SaintMartin» (p. 957). Su memoria reconstruye aquel primer viaje y otros posteriores a la capital francesa, una recuperación que se ha ido metamorfoseando a lo largo del tiempo y, a partir de unas claves de recuperación, brota el recuerdo con una riqueza informativa inusitada. Este hábito de deambular sin rumbo, adquirido en sus viajes y estancias prolongadas fuera de casa, fueron configurando un personaje con desapego a proyectos vitales que le alejaran de su objetivo primordial: su fuerte vocación literaria. Esta costumbre le lleva a confesar al lector: «Yo no sé si he nacido en mitad de la calle, pero es ahí donde he vivido» (p. 963).

Hay grandes silencios en esta autobiografía. El narrador va a eludir casi por completo su vida privada durante largos periodos, pero va a rememorar experiencias viajeras donde muestra interés por captar atmósferas, segmentos de unas realidades donde se mezclan los itinerarios precisos, la focalización asombrada, la crítica mordaz en algunos casos, velada en otros; impresiones siempre expresadas con una sucinta economía narrativa. Entre 1960 y 1964, Otero realiza largos viajes a los países donde ha triunfado la revolución socialista, primero a la Unión Soviética y China, invitado por la Asociación

16 Jorge Semprún, Autobiografía de Federico Sánchez. Barcelona, Planeta, 1977, p. 96 narra sus impresiones en la relación de amistad que mantuvo con Blas de Otero en el París de 1952. 
Internacional de Autores e intenta conocer de un modo directo la realidad de aquellos países donde las masas habían asumido un papel protagonista.

Ahora estoy en Moscú, es mi primer viaje al campo socialista y la mañana está nublada, friísima, pero los rusos caminan parsimoniosos, centrados, directamente al porvenir. Las tersas rusas, sus suaves pupilas, endulzan los grandes almacenes de la Plaza Roja, el amplio vestíbulo del Bolshoi. Allí vi muchas cosas, malas y muy buenas, e incluso algún compatriota eunuco y tiranuelo. Sobre las cumbres del Cáucaso, volando hacia la República Popular China, contemplo las amarillentas arenas de Mongolia, desciendo la escalerilla del avión en Pekín, una linda muchacha llega hacia mi con un gran ramo de flores intensamente perfumadas (p. 955) [...]. Aquí en Shanghái tengo poco que hacer, escucho música española, zarzuela, jondo, y escribo los veinticinco poemas chinos que no sé cuándo publicaré (p. 966).

El sujeto narrativo deja que fluyan los recuerdos en una peculiar discontinuidad, como si evocara el pasado de un personaje maduro en una serie de secuencias atemporales. Registra y calla en la misma medida, tanto en lo que respecta a la vida privada como a la pública. El larguísimo tiempo de silencio que siguió a la guerra civil, donde nada podía ocurrir, es también, en parte, protagonista de esta autobiografía.

En 1964, durante una de sus estancias en París, Otero recibe una invitación para formar parte en La Habana del jurado del premio internacional de poesía Casa de las Américas, «lo que le ofrecía la posibilidad de conocer una revolución popular sin trabas lingüísticas para comunicarse. En Cuba vivió poco más de dos años, desde el 22 de enero de 1964 hasta el 28 de abril de 1968, fecha en que vuelve definitivamente a España. Entre una y otra fecha residió un año en Bilbao, con varias estancias en París, Praga y Moscú» ${ }^{17}$. A los pocos meses de llegar se casa —el 25 de marzo de 1964 — con una joven ciudadana cubana, Yolanda Pina, divorciada, quien tenía un hijo de seis años del matrimonio anterior, a quien conoció en la biblioteca de la Unión de Escritores y Artistas de Cuba, donde trabajaba como mecanógrafa. El matrimonio marcha en 1965 a la Unión Soviética y, poco después, de nuevo a Cuba, donde se divorciarán el 20 de noviembre de 1967. Otero «trabaja en el periódico España Republicana y da recitales y conferencias por toda la isla ${ }^{18}$, lo que le permitió — según testimonios orales de su segunda mujer, Sabina de la Cruz — pagar todos los costes que le ocasionó el divorcio ${ }^{19}$. Se divorciarán el 20 de noviembre de $1967^{20}$.

${ }^{17}$ Sabina de la Cruz, «La vida de un poeta». Blas de Otero. Obra completa, op. cit., p. 72. Sobre la presencia de la isla caribeña en la obra oteriana, vid, Evelyne Martín Hernández, «El antillano». Volver a Blas de Otero. (Monográfico). Zurgai, Bilbao, (julio,1998), pp. 46-50.

18 Sabina de la Cruz, «Notas biográficas» en Blas de Otero. Verso y prosa. Madrid, Cátedra, 1984, p. 118.

${ }^{19}$ He tenido acceso a la documentación de la sentencia de divorcio expedida en el Juzgado de Primera Instancia de La Habana. Este divorcio fue solicitado por Blas de Otero y a él se allanó la esposa, atendiendo a los siguientes motivos: «Que desde los primeros tiempos de la vida conyugal empezaron a surgir desavenencias entre los cónyuges, haciendo totalmente anormal la vida conyugal debido a la incompatibilidad de caracteres entre los mismos por lo que se separaron y viven en distintos domicilios, rompiendo la vida conyugal, situación que aún persiste.» El 23 de octubre de 1986 fue ejecutada en Madrid esta sentencia de divorcio por la Sala Primera del Tribunal Supremo.

${ }^{20}$ Fernando Valls, en el artículo anteriormente citado, aporta algunos datos sobre la estancia del poeta en la isla caribeña y reclama información detallada y fidedigna sobre su azarosa existencia en esos años. En la correspondencia que mantuvieron Otero y Max Aub, que he tenido ocasión de consultar gracias a la amabilidad de la Fundación Max Aub en Segorbe, hay una carta que el poeta bilbaíno remite al amigo desde Bilbao, con fecha 1 de enero de 1965, en la que además de desearle «un venturoso y fructífero Año Nuevo», le dice: «Aquí 
De la isla caribeña trajo la belleza de sus paisajes y el respeto por sus gentes. Su entusiasmo por la revolución cubana la plasmó ya con rotundidad en Historias fingidas y verdaderas y en otros poemas de Hojas de Madrid y ahora evoca el recorrido por sus ciudades y calles, escucha a los ciudadanos, se empapa de su habla, los ve vivir hermanados y protagonistas de su futuro, comparte el esfuerzo con este pueblo y confiesa: «Lo que más me gusta de Cuba es su valor y su sensualidad. Cuba bonita y valiente. Cuba del nuevo mundo, donde Fidel descubrió mejor que Colón la tierra del hombre (p. 962)», y recorre la isla por cualquier medio para acercarse al pueblo: «subo por la Sierra Maestra o rodeo la bahía de Cienfuegos, después de haber conversado con los compañeritos de Secundaria Básica» (p. 955). Evoca la primera vez que vio a Fidel Castro en los estudios de la CMQ, a su regreso de la Unión Soviética, explicando al pueblo el convenio del azúcar $^{21}$ y le retrata así:

Fidel es un niño grande con una cabeza bien asentada sobre sus anchas espaldas, lo que le permite mantener el control aun en los momentos de mayor arrebato. Fidel habla al corazón de su pueblo, pero también le ofrece números, problemas expuestos al detalle, y el pueblo lo ama como a un ídolo de carne y hueso. Nadie pondrá su pezuña aquí, están dispuestos hasta la muerte, más allá de un nuevo Vietnam asombro de América y del mundo (p. 963).

Otra figura que le impresiona es el Che y así lo expresa: «Allí estaba el Che, con sus ojos de pillo, de listo hasta la punta del bisturí (p. 962) ${ }^{22} \gg$. Y recuerda la «impresionante noche cuando intenté acercarme a la plaza de la Revolución en el inmenso homenaje a su muerte, tras tres días de silencio y dolor y rabia, escuchando una vez y otra la Quinta sinfonía por todas las radios de la ciudad» ${ }^{23}$ (p. 962). Sin embargo, apenas emite unas palabras sobre las relaciones literarias que mantuvo en la isla, sobre los encuentros con personajes del mundo de la cultura ${ }^{24}$. Solo en una ocasión se refiere a una lectura de textos inéditos de las obras que tenía entre manos que se celebró en la Unión de Escritores y Artistas de Cuba, con estas palabras:

ando otra vez por mi tierra, mi estancia en Cuba se prolongó y fue muy provechosa. Allí me casé. Estamos contentos». Acompaña la noticia con una tarjeta que dice: «Blas de Otero y Yolanda Pina se casarán en La Habana, el día 25 de Marzo de 1964. Les complacerá ver a Vd. en el Vino Español, 12:30 p.m. S.A.C.E. (Centro Gallego) Parque Central».

${ }_{21}$ El circuito radial CMQ fue una cadena de radio y televisión cubana ubicada en La Habana, en el barrio de Vedado.

${ }^{22}$ Entre los veinticinco poemas que conforman el manuscrito de Mientras (expte. $\mathrm{n}^{\mathrm{o}}$ 7749-70), que el editor de Javalambre entregó en el Ministerio de Información y Turismo, Dirección General de Cultura Popular para solicitar la tarjeta de publicación, está el poema «Tania», que fue censurado y excluido del conjunto en el momento de la publicación. Algunos versos hacen referencia al Che y a este mismo momento: «[...] en pie América Latina y camino tras el Che, / y recuerdo su mirada de aquella noche en el estudio de la CMQ / o su imprevisible salida de una máquina frente a la entrada del Habana Libre, / y juro que le vengaremos / [...]». Los avatares que sufrió este manuscrito pueden consultarse en mi artículo «Blas de Otero y la censura española. Desde 1949 hasta la transición política. Segunda parte: de Que trata de España (1964) a Todos mis sonetos (1977)», art. cit., pp. 170-171.

${ }^{23}$ Che Guevara fue herido y capturado en una emboscada por el ejército boliviano el 8 de octubre de 1967. Al día siguiente fue ejecutado en el poblado de la Higuera.

${ }^{24}$ No podemos olvidar que el poeta llevó a Cuba la edición completa de su último libro Que trata de España del que se hizo en La Habana una amplia edición por la Editorial Nacional. (Blas de Otero, Que trata de España. La Habana, Editora del Consejo Nacional de Cultura. Editorial Nacional de Cultura, 1964. $1^{\mathrm{a}}$ parte: Libro I, Pido la paz y la palabra. Libro II, En castellano. $2^{\mathrm{a}}$ parte: Libro III, Que trata de España.) 
[...] Esta lectura que voy a ofrecerles a ustedes será breve, un poco variada, pues comprenderá diversos nuevos libros, Historias fingidas y verdaderas, URSS y Con Cuba. No he pretendido en este último hacer nada definitivo, me he tenido que limitar a mi experiencia, dentro de mi propia expresión renovada. Veo a Nicolás con su noble rostro mulato, a Heberto Padilla con su conciencia en crisis, a Onelio, tan buen cuentista, tan de su tierra ${ }^{25}$ (p. 955).

Son también infrecuentes los comentarios sobre escritores españoles contemporáneos con los que tuvo relaciones amistosas más o menos breves o duraderas. Nunca se mostró proclive a sacerdocios o profetas distinguidos, ni se dejó dirigir por amigos influyentes o ideologías.

Ocasionalmente se desatan los mecanismos de la memoria, siempre de rigurosa medición, y el propio pasado se ordena selectivamente en la dirección de discernir el sentido último de experiencias pretéritas que ahora se iluminan con una nueva luz, como ocurre con la expresión de las crisis depresivas que le acompañaron toda la vida y a las que ha aludido en otros momentos en prosa y en verso. El poeta localiza la primera manifestación depresiva a los dieciséis años y en la prosa «Rotura» de Historias fingidas y verdaderas avanza la clave interpretativa ${ }^{26}$. A lo largo de su vida necesitó cuidados en múltiples ocasiones. La ironía distanciadora con la que presenta estos difíciles periodos desdibuja la frontera entre lo vivido y lo narrado.

Y los amplios hospitales que me cobijaron en París, y Shanghái, y La Habana. Aquellas compañeras del Hospital Naval, en La Habana del Este. Las enfermeras mulatas, tan decididas, tan eficaces, tan cachondas. Me están poniendo una inyección hasta el puño, pero te miro a los ojos y muevo los labios así, como a ti te gusta. [...] (956). Lo que no puedo contar a nadie, lo que solo algunos conocen a retazos, son las iras del espíritu, la casa oscura de Usúrbil, el ejemplo de la torre Eiffel, las alambradas de Pekín, el chicle pegado al pensamiento en La Habana, qué difícil de comprender (p. 963).

De Cuba vuelve a Madrid gravemente enfermo y pocos días después es operado de un tumor canceroso muy grave. Inmediatamente, y de forma casual, se produce el reencuentro con Sabina de la Cruz. «Puedo decir — señala la profesora de la Cruz- que ocurrió sin darnos cuenta. Aquel amor que había sido corto, pero muy hermoso, fue renaciendo sin decirnos nada, acaso sin querérnoslo confesar a nosotros mismos. Él, porque su situación era muy mala. Yo, porque mi educación me impedía plantearme una relación fuera de un entorno tradicional. Lo cierto es que resurgió y de una manera tan avasalladora en esas circunstancias además tan trágicas, que pudo con todo ${ }^{27}$. Once años le quedan aún de vida contra todos los pronósticos. La voz presente del sujeto ha-

${ }^{25}$ Alude, como el lector ya habrá descubierto, a algunos escritores cubanos -Nicolás Guillén, Padilla y Onelio Jorge Cardoso-.

${ }^{26}$ Sabina de la Cruz, «Porvenir y Brisa: Sabina de la Cruz con Blas de Otero», entrevista citada, p. 200, explica que la vocación del poeta fue muy temprana y las terribles circunstancias familiares que tuvo que afrontar torcieron su destino; tuvo que dejar sus sueños y seguir el camino que había iniciado el hermano muerto. «La lucha por recuperarlo marcó al joven abogado, y la ruptura con los proyectos familiares desencadenó las depresiones que le acompañaron toda la vida.» Tenía un proyecto desde niño y luchó toda la vida por cumplirlo.

${ }_{27}$ Gloria Díez, «Blas de Otero fue un ser libre». El Correo Español - El Pueblo Vasco, Bilbao (20 de julio, 1983), p. 35. 
blante fija con mucha precisión el espacio y el momento de la escritura y traza ahora una crónica de sus condiciones de vida.

Ahora estoy otra vez en Madrid, febrero de 1969 [...] Mi salud está recuperándose. La mujer que me acompaña es buena, inteligente, cariñosa. España anda mal, como siempre. Escribo mucho y escucho mucha música [...] (962). Estoy sobre la mesa de operaciones, un certero tajo y al carajo el tumor, peor pudo haber sido...Vino la primavera y escribí como un hambriento en el ático del Barrio Blanco, y subí a Vizcaya y pasé a Barcelona a preparar la profilaxis, y luego vino lo peor en la calle de Vitrubio, viva moneda que nunca quisiera se repitiese. Esas radiaciones de cobalto, cuando me encontraba solo en el Hotel-Residencia don Ramón de la Cruz y todas mis fuerzas las concentraba para poder tomar un taxi a media tarde y trasladarme a la clínica; salía medio borracho y deambulaba dando tumbos... Así es la vida, que no me vengan a mí con teorías porque lo peor que hay en el mundo es el dolor. Mi terquedad es indomable, dirigida siempre hacia los cuatro puntos cardinales de toda mi vida: el arte, la mujer, la justicia y pasear por la calle (p. 963).

Otro fenómeno constante del carácter reflexivo de esta autobiografía es el interés por cifrar sus influencias literarias, el espacio de su primera nutrición como poeta. Lector infatigable desde la más temprana infancia y con una memoria prodigiosa para recordar y reproducir lo leído, en su poesía elaborará todo tipo de estrategias para incorporar, manipular y servirse de citas de otros autores. De casi todos ellos se hace eco en Historia (casi) de mi vida:

Uno de mis primeros poetas predilectos fue - y sigue siéndolo- José María Gabriel y Galán. Porque sabed, críticos cegatos, poetas miopes y pedantes, que Gabriel y Galán es un buen, y a veces muy buen poeta. Leed, por ejemplo, Castellanas, y os podréis dar cuenta de que el mismo fray Luis, Lope o Machado quedan muy justamente a su altura (p. 959) [...]. Los primeros versos los vi en mi adolescencia madrileña en el Tesoro de la juventud. Y algunos de Juan Ramón. Después, yendo a Valladolid a examinarme de las asignaturas de Derecho, leía a Gabriel y Galán. Luego entré en la Generación del 27 [...]. Lorca siempre me gustó por su condensación, su corporeidad. Unamuno, al que intenté leer años más tarde, no sabe manejar el verso [...]. Y leía y leía a fray Luis, y también a Quevedo. Y el Cancionero popular y tradicional y el Romancero, sencillas cumbres de la poesía castellana. Al fin conocí a Nâzim Hikmet (p. 966).

Otro motivo recurrente es la reflexión sobre el oficio de escritor; incide en la función metapoética, el verso trata de la propia construcción del verso, y en la autobiografía analiza pormenorizadamente el complejo proceso de la creación, la búsqueda de nuevas formas de expresión, la evolución de la propia obra de poeta desde los inicios de su carrera literaria. En estas líneas resuelve algunos de los problemas que la crítica ha tardado años en desentrañar.

Cuando escogí los poemas para construir Ángel fieramente humano llevaba ya laborando tres o cuatro años bajo control riguroso. El material era extenso y así pude formar un libro apretado. Es el mismo que Redoble de conciencia y los poemas que posteriormente incluí en Ancia. Al ir escribiendo los últimos poemas de esta etapa yo ya presentía, lejana y hondamente, la necesidad de cambio, tanto temático como formal. Así que todo ello advino gradualmente hasta hoy o mañana, y de manera más brusca en Hojas de Madrid, a mi regreso de Cuba, en 1968 (p. 960). [...] Intenté una ruptura del ritmo con En castellano, después del cercenamiento de Pido la paz y la palabra. Los poemas de Que trata de España los fui escri- 
biendo en Moscú, España, París... Aquí he utilizado todo tipo de material, procedimiento que presentía como una posibilidad desde 1952 [...] Versos ajenos — literales o cercanos—, cartas. Fragmentos de discursos o noticias, estadísticas... Lo acentué en los libros «URSS» Cuba», de Poesía e Historia ${ }^{28}$. Solo es necesario que se mantenga la proporción, el cuerpo orgánico que es todo poema (p. 961).

La voz narrativa enuncia y explica los principios estéticos que han regido su creación, informa al lector sobre sus ideas literarias y el ejercicio de esas ideas. La unidad temática y formal de Ángel fieramente humano y Redoble de conciencia se refuerza al publicarlos en un conjunto, Ancia y nuevos temas y nuevo lenguaje ensaya en los libros del ciclo de la poesía histórica o social. El afán por encontrar nuevas formas es parte importantísima de su personalidad poética, como lo demostró a lo largo de toda su obra, y una de las claves de su originalidad. Declaraciones como las que encierran estas líneas respaldan la manifestación de propósitos autobiográficos del protagonista y hacen eficaz el efecto de verdad autobiográfica. Su prosa autobiográfica logra un timbre de veracidad del que otros textos — sean o no ficción- carecen.

${ }^{28}$ Elena Perulero, «Poesía e Historia, un proyecto truncado». Boletín de la Fundación Federico García Lorca. Homenaje a Blas de Otero. XXII, 43 (2008), pp. 129-150. 
